\title{
Article \\ A Prospective, Randomised, Controlled, Split-Face Clinical Trial to Assess the Safety and the Efficacy of Cold Atmospheric Plasma in the Treatment of Acne Vulgaris
}

\author{
Sigrid Karrer ${ }^{1, *}$, Mark Berneburg ${ }^{1}$, Florian Zeman ${ }^{2}$, Michael Koller ${ }^{2}$ and Karolina Müller ${ }^{2}$ (D) \\ 1 Department of Dermatology, University Hospital Regensburg, Franz-Josef-Strauss Allee 11, \\ 93053 Regensburg, Germany; mark.berneburg@ukr.de \\ 2 Centre for Clinical Studies, University Hospital Regensburg, Franz-Josef-Strauss Allee 11, \\ 93053 Regensburg, Germany; florian.zeman@ukr.de (F.Z.); michael.koller@ukr.de (M.K.); \\ karolina.mueller@ukr.de (K.M.) \\ * Correspondence: sigrid.karrer@ukr.de; Tel.: +49-941-944-9656
}

\section{check for} updates

Citation: Karrer, S.; Berneburg, M.; Zeman, F.; Koller, M.; Müller, K. A Prospective, Randomised, Controlled, Split-Face Clinical Trial to Assess the Safety and the Efficacy of Cold

Atmospheric Plasma in the Treatment of Acne Vulgaris. Appl. Sci. 2021, 11, 11181. https://doi.org/10.3390/ app112311181

Academic Editors: Gabriele Cristoforetti and Vincenzo Palleschi

Received: 22 October 2021

Accepted: 23 November 2021

Published: 25 November 2021

Publisher's Note: MDPI stays neutral with regard to jurisdictional claims in published maps and institutional affiliations.

Copyright: (c) 2021 by the authors. Licensee MDPI, Basel, Switzerland. This article is an open access article distributed under the terms and conditions of the Creative Commons Attribution (CC BY) license (https:// creativecommons.org/licenses/by/ $4.0 /)$.

\begin{abstract}
The increase in antibiotic resistance requires effective non-antibiotic therapies for acne. Cold atmospheric plasma (CAP) inactivates bacteria and improves wound healing, but its effect on acne has not been investigated. The objective of this controlled split-face study was to assess safety and efficacy of CAP in moderate acne. One side of the face received 8-10 treatments with cold helium plasma within 4-6 weeks; follow-up was two and four weeks thereafter. Acne lesions were counted, followed by global acne severity ratings. Of the 34 patients included, 29 completed the study. No serious adverse events occurred. The two facial sides did not significantly differ in the number of inflammatory and non-inflammatory lesions. An interaction effect of number and type of treatment was found for inflammatory lesions. Lesion reduction after 10 treatments was significantly higher on the treated than on the untreated side. Percentage of patients reporting improved aesthetics was higher for the treated than for the untreated side after treatment completion (79\% vs. 45\%) and at the two- ( $72 \%$ vs. $45 \%$ ) and four-week follow-up (79\% vs. $52 \%$ ). In conclusion, CAP was safe with excellent tolerability, showed moderate reduction in acne lesions and led to higher patient-based ratings of aesthetics than non-treatment.
\end{abstract}

Keywords: acne; antibiotic resistance; CAP; cold plasma

\section{Introduction}

Acne vulgaris is the most common skin disease with a prevalence of acne ranging from $35 \%$ to close to $100 \%$ of adolescents having acne at some point [1-3]. Common treatments consisting of topically applied retinoids or benzoyl peroxide usually cause intolerance reactions, such as dryness of the skin, scaling, redness, irritation and even allergies [2]. Frequently used oral antibiotics may cause nausea, diarrhoea, disruption of the microbiome, photosensitivity, drug reactions and allergies [2]. Especially the prolonged use of oral or topical antibiotics leading to bacterial resistance is of major concern among dermatologists [4]. Because of side effects, patient adherence to acne treatment is often low, resulting in negative therapeutic outcomes, permanent scarring and negative psychosocial consequences. Better tolerable and effective treatments for acne are needed to improve adherence to therapy and to limit antibiotic use.

Cold atmospheric plasma (CAP) is a rapidly developing technology with a great potential in medicine [5-7]. Plasma is a partly ionised gas composed of a highly reactive mix of ions and electrons, reactive oxygen and nitrogen species, electric fields and ultraviolet radiation. Natural plasma is usually hot, but non-thermal plasma can be generated in normal atmosphere to be used in humans. In the past years, several CAP devices have been developed. Unique compositions of active plasma can be generated upon ignition, 
depending on the different plasma technologies available, the ionization processes, the density and temperature, and the gas used [8]. CAP has been shown to be very effective not only against all types of bacteria including multi-resistant germs but also against biofilm-forming bacteria, viruses, fungi and spores [9-12]. The suggested mechanisms for the antimicrobial effects include lysis of microorganisms due to accumulation of charged particles and oxidative damage to cytoplasmic membranes, bacterial proteins and DNA [13]. Treatment with CAP may therefore constitute an effective alternative to antiseptics and antibiotics for the eradication of pathogens. In dermatology, CAP is being used for treating chronic leg ulcers [14-19], acute wounds [20], shingles [21], skin aging [22] and actinic keratosis [23]. In wounds, CAP has been found to not only significantly reduce the bacterial load but also to accelerate wound healing [14-19]. So far, no serious adverse events have been described after CAP treatment; furthermore, no mutagenic potential has been found [24-26]. The advantage of CAP is its pain-free, non-invasive, easy and fast application. Bacterial resistance and allergic or toxic reactions are very unlikely because of its physical mode of action.

Because of its gaseous form, CAP can penetrate into hair follicles [27], in which inflammation is triggered by Cutibacterium acnes in patients with acne [2,3]. We hypothesised that the antibacterial and anti-inflammatory properties of CAP have the potential to improve skin affected by acne. Therefore, we conducted a controlled, randomised, split-face study to investigate the safety and efficacy of CAP in patients with moderate acne vulgaris.

\section{Materials and Methods}

\subsection{Study Design and Sample Size Rationale}

This trial was designed as a prospective, randomised, controlled, single-blinded, single-centre study. A split-face design was used to compare CAP treatment to no treatment in patients with moderate papulopustular facial acne. Based on the initially defined primary efficacy endpoint of mean percentage reduction in the total number of lesions between the treated and the untreated side of the face, 37 patients would enable the detection of an absolute difference of $20 \%$ with at least $80 \%$ power and a $5 \%$ level of significance if the standard deviation of this difference is no higher than $42 \%$. Adjusting for a drop-out rate of $10 \%$, a total of 41 patients was set as the recruitment goal.

\subsection{Ethical Considerations and Study Registration}

This study was conducted in accordance with the German Medical Device Law (\$22a Medizinproduktegesetz, MPG), the Harmonised Tripartite Guideline for Good Clinical Practice (ICH-GCP E6), the International Standard Organization (ISO); ISO 14155-1; ISO 14155-2, and the Declaration of Helsinki (64th WMA General Assembly, Fortaleza, Brazil, October 2013). The study was approved by the Ethics Committee of the University of Regensburg (reference number: 16-121-0120) and the German Federal Institute for Drugs and Medical Devices (BfArM, reference number: 94.1.01-5660-10252). This federal institute did not permit the inclusion of patients younger than 18 years of age in this study, as originally planned.

The study was registered with the study register DRKS (Deutsches Register Klinischer Studien, registration number DRKS00025008), was submitted to the WHO and is searchable via its Meta-registry (http:/ / apps.who.int/trialsearch, (accessed on 7 April 2021)).

\subsection{Inclusion and Exclusion Criteria}

Key inclusion criteria were age of at least 18 years, moderate papulopustular acne with lesions on both sides of the face, an Investigator Global Assessment (IGA) scale score of 3 at screening, a negative pregnancy test in female subjects, written informed consent and failure to respond to standard acne treatments.

Key exclusion criteria were concomitant topical (during the four weeks preceding study treatment) and systemic (during the eight weeks preceding study treatment) acne treatment, planned topical or systemic acne treatment in the next ten weeks, immunosup- 
pression, severe internal diseases, pregnancy, lactation, active implants and severe ocular and facial diseases.

\subsection{Study Procedures}

The screening visit took place after patients had given their written informed consent. Prior to the first treatment, eligibility criteria were checked, the medical history was documented, and CAP treatment to the left or right side of the face was randomised according to a block randomisation scheme.

Inflammatory (papules and pustules) and non-inflammatory lesions (comedones) of each side of the face were counted by a dermatologist blinded to the type of treatment at six time points: screening, before treatment 1 (baseline), before treatment 4 , before the last treatment as well as two and four weeks after the last treatment.

CAP treatment was conducted with the BioWeld1 system (IonMed Ltd., Yokneam, Israel), which had been certified as class IIa medical device for surgical wound closure. The BioWeld1 system was designed to enable controlled cold plasma $\left(<40^{\circ} \mathrm{C}\right)$ ejection. When the device is connected and turned on, a helium gas flows from a tank and enters a plasma tip through the hand piece, in which the helium gas is ionised by radiofrequency energy and transformed into plasma. The plasma flows out of a handheld tip and interacts with the skin (Figure 1). Thus, plasma was applied to the facial skin through the plasma tip that was slowly moved over the skin.

All patients received 8-10 CAP treatments within four to six weeks; the follow-up period was two and four weeks after treatment completion. According to randomisation, each treatment was conducted on the same side of the face, while the other side of the face remained untreated. During treatment, the patients had to wear goggles for eye protection. The area of the skin was continuously exposed to CAP for less than $10 \mathrm{~s}$ with a maximum of two repetitions per treatment. The tip was supplied sterilised for single use. The duration of CAP treatment was documented at each visit.

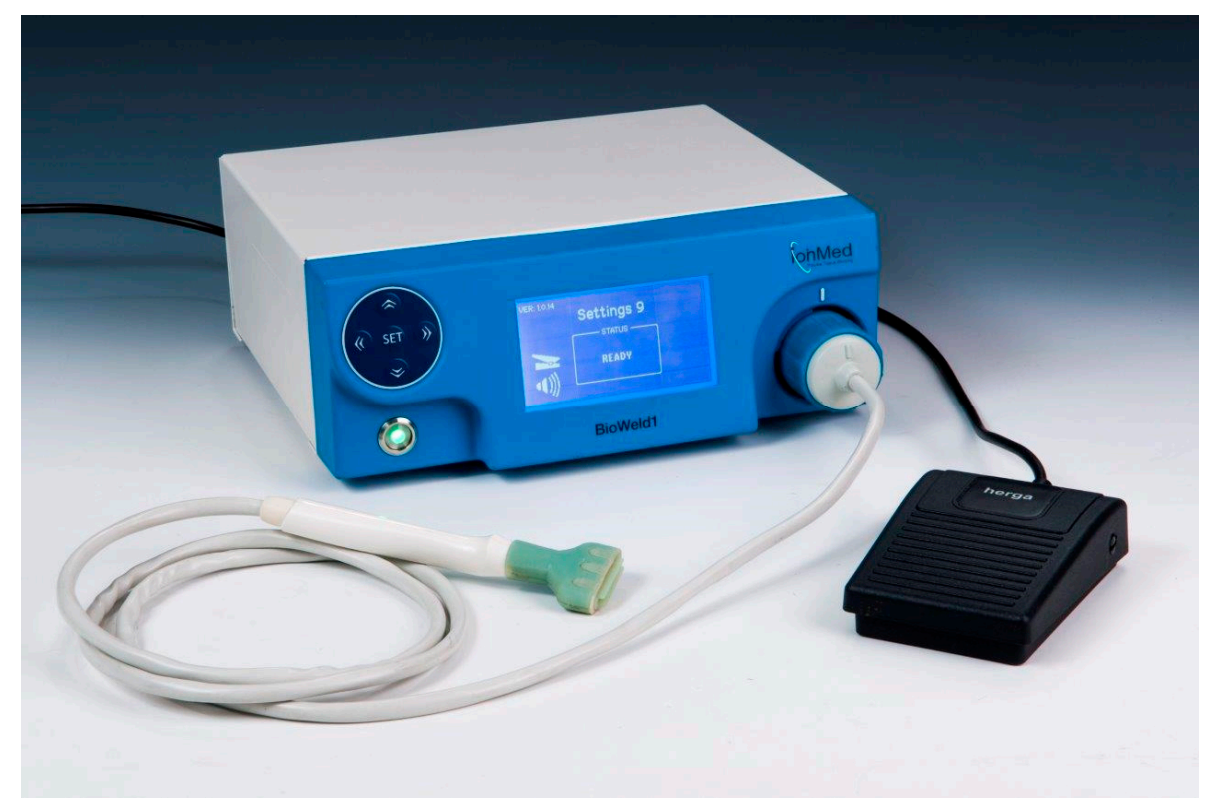

Figure 1. The BioWeld1 System consists of a plasma ejector base unit (height $12 \mathrm{~cm}$, width $32 \mathrm{~cm}$ ), a hand-piece with a cable, a plasma tip and a foot switch.

\subsection{Patient Enrolment}

The first patient entered the study in November 2016, and the last patient finished the study in March 2018. 
The study was closed by the sponsor IonMed Ltd. after 37 patients had been enrolled. The decision on premature closure was purely business-related and not due to any concerns regarding safety or efficacy.

Three patients were excluded from the analyses because they dropped out before the first treatment. Five patients dropped out during the treatment period because of organisational reasons ( 2 patients after 2 treatments, 2 patients after 5 treatments, and 1 patient after 7 treatments). The remaining 29 patients completed the study (Figure 2).

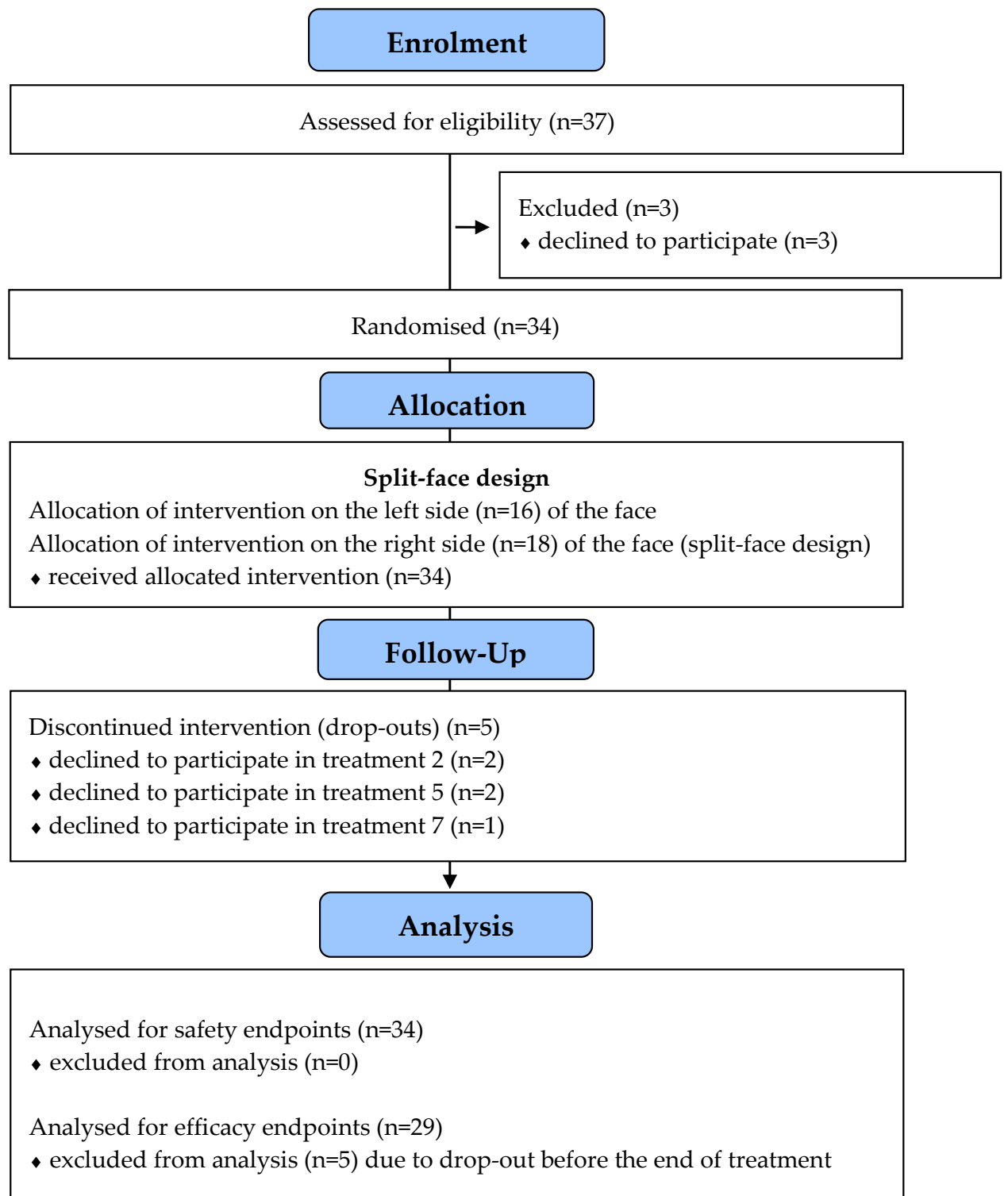

Figure 2. Flow chart diagram.

\subsection{Primary Endpoints}

The primary objective of this study was to evaluate the safety and efficacy of the cold helium plasma device BioWeld1 in patients with moderate facial papulopustular acne vulgaris.

The primary safety endpoint was the unanticipated device-related (serious) adverse event ((S)AE) rate. (S)AEs were continually assessed after the first treatment until study completion at the four-week follow-up. All (S)AEs deemed clinically significant by the investigator were recorded.

The primary efficacy end-point was the reduction in the mean percentage change in the number of lesions on the treated side versus the untreated side between baseline and 
completion of the treatment protocol (week 4-6) in at least one of the two types of lesions (inflammatory and non-inflammatory lesions) and overall. Because acne lesions are commonly differentiated into inflammatory and non-inflammatory lesions, and inflammatory lesions are expected to respond better to treatment, efficacy was analysed separately for both types of lesions and not for the total of all lesions. Moreover, the relative change turned out to be an inappropriate measure because of the count of zero lesions at baseline.

Thus, we used the absolute change from baseline to treatment completion as a primary endpoint. In addition, the mean percentage change was calculated on the basis of the mean absolute change.

\subsection{Secondary Endpoints}

According to the protocol, the following secondary endpoints were examined: The change in the number of inflammatory and non-inflammatory acne lesions from baseline to the two-week and four-week follow-ups compared between the CAP-treated and the untreated side.

Subject satisfaction was assessed separately for the treated and the untreated side after the last treatment as well as two and four weeks after the last treatment, using the Global Aesthetic Improvement Scale (GAIS).

Improvement of the skin condition, as determined by the Investigator Global Assessment (IGA) score, was separately assessed by a blinded dermatologist for each side of the face at baseline, at the last treatment as well as two and four weeks after the last treatment. GAIS and IGA ratings are presented in Table 1.

After completion of each CAP treatment, the patients were asked to mark their pain level on a visual analogue scale (VAS) ranging from 0 (no pain) to 10 (insufferable pain).

Table 1. Ratings of secondary efficacy endpoints.

\begin{tabular}{|c|c|}
\hline Global Aesthetic Improvement Scale (GAIS) & Investigator Global Assessment (IGA) \\
\hline $\begin{array}{l}3 \text { = very much improved: Optimal cosmetic } \\
\text { result for the treatment in this subject. }\end{array}$ & $\begin{array}{l}0=\text { clear skin with no inflammatory or } \\
\text { non-inflammatory lesion }\end{array}$ \\
\hline $\begin{array}{l}2=\text { much improved: Marked improvement in } \\
\text { appearance from the initial condition but not } \\
\text { completely optimal for this subject. }\end{array}$ & $\begin{array}{l}1=\text { almost clear, rare non-inflammatory lesions } \\
\text { with no more than one small inflammatory } \\
\text { lesion }\end{array}$ \\
\hline $\begin{array}{l}1=\text { improved: Obvious improvement in } \\
\text { appearance from the initial condition. }\end{array}$ & $\begin{array}{l}2=\text { mild, some non-inflammatory lesions, no } \\
\text { more than a few inflammatory lesions }\end{array}$ \\
\hline $\begin{array}{l}0=\text { no change: The appearance is essentially } \\
\text { the same as baseline. }\end{array}$ & $\begin{array}{l}3=\text { moderate, up to many non-inflammatory } \\
\text { lesions and may have some inflammatory } \\
\text { lesions, but no more than one small nodular } \\
\text { lesion }\end{array}$ \\
\hline $\begin{array}{l}-1=\text { worse: The appearance is worse than the } \\
\text { original condition. }\end{array}$ & $\begin{array}{l}4=\text { severe, up to many non-inflammatory and } \\
\text { inflammatory lesions, but no more than a few } \\
\text { nodular lesions. }\end{array}$ \\
\hline \multicolumn{2}{|l|}{$\begin{array}{l}-2=\text { much worse: Marked worsening in } \\
\text { appearance from the initial condition. }\end{array}$} \\
\hline $\begin{array}{l}-3=\text { very much worse: Obvious worsening in } \\
\text { appearance from the initial condition. }\end{array}$ & \\
\hline
\end{tabular}

\subsection{Statistical Analyses}

Descriptive analyses are presented for demographic and treatment-related data, lesion counts and the safety endpoints, using frequency $(n)$, percentage $(\%)$ and mean $(\mathrm{m}) \pm$ standard deviation (sd).

For the primary efficacy endpoints, mixed linear models (MLMs) were calculated to compare the change in lesions between the treated and the untreated side separately for the two types of lesions from baseline to treatment completion. The MLMs (maximum 
likelihood method, unstructured repeated covariance type) included the following fixed effects: the number of treatments (8 vs. 10 treatments), the type of treatment (CAP vs. no treatment) and the number of treatments by treatment type interaction term. Baseline lesion counts of the treated and the untreated side are entered as a covariate. Estimated means with corresponding 95\% confidence intervals (CI) are reported as effect estimates. Additionally, the percentages of mean change in the number of inflammatory and noninflammatory lesions are provided for the treated and untreated side.

The secondary efficacy endpoints, i.e., the change in the number of lesions from baseline to the two- and four-week follow-ups, were also analysed with regard to the primary efficacy endpoints.

In addition to the analyses described in the protocol, the course of the number of inflammatory and non-inflammatory lesions from baseline to the four-week follow-up was assessed for the treated and untreated side to explore the impact of treatment on the reduction in lesions by means of MLMs (maximum likelihood method, unstructured repeated covariance type) including time, the number of treatments and the interaction of time and number of treatments as fixed effects.

Wilcoxon tests were conducted to compare GAIS and IGA scores between the treated and the untreated side at completion of treatment and at the two- and four-week follow-ups. The pain ratings were averaged over each treatment and are descriptively reported.

The level of significance was set at $p \leq 0.05$ for all tests. Because data analyses are of exploratory manner, no adjustments for multiple testing were conducted.

Statistical analysis was done using the software package SPSS (Version 26, SPSS Inc., Chicago, IL, USA).

\section{Results}

\subsection{Demographic and Treatment-Related Data}

Table 2 shows the demographic data of the patients. The mean duration of treating one side of the face with the BioWeld1 system was 3:06 \pm 0:38 min per session; the minimum was 1:15 $\mathrm{min}$ and the maximum 5:40 $\mathrm{min}$ ( $n=270$ recordings).

Table 2. Demographic data of patients.

\begin{tabular}{ccc}
\hline & Safety Population & Primary Efficacy Endpoint Population \\
\hline Number of patients & 34 & 29 \\
\hline Age in years mean \pm sd (range) & $26.1 \pm 8.3(18-54)$ & $26.9 \pm 9.0(18-54)$ \\
\hline Sex & & $4(13.8 \%)$ \\
\hline men & $5(14.7 \%)$ & $25(86.2 \%)$ \\
\hline women & $29(85.3 \%)$ & $15(51.7 \%)$ \\
\hline Fitzpatrick type & $13(44.8 \%)$ \\
\hline II & $19(55.9 \%)$ & $1(3.4 \%)$ \\
\hline III & $14(41.2 \%)$ & \\
\hline IV & $1(2.9 \%)$ & $29(100 \%)$ \\
\hline Ethnic origin & $34(100 \%)$ &
\end{tabular}

\subsection{Primary Safety Endpoints}

No SAEs were observed. In total, two AEs in two patients were documented: pain and redness during one treatment and pain during another treatment. Both AEs were of mild intensity, and no actions had to be taken. AEs were resolved without sequelae. AEs were related to the treatment. 


\subsection{Secondary Safety Endpoint}

Pain during treatment ( $n=267$ ratings) ranged from 0 to 4.6 , but the majority of the ratings $(80.5 \%)$ were 0 (no pain).

\subsection{Course of the Number of Lesions}

In total, 29 patients had a valid lesion count at baseline, at treatment completion as well as at two and four weeks after treatment completion. The courses of the inflammatory and non-inflammatory lesion counts are presented separately for the treated and the untreated side in Figure 3. The treated sides showed a significant decrease in inflammatory lesions $(p=0.007)$ but not in non-inflammatory lesions $(p=0.288)$. The untreated sides neither showed any reduction in inflammatory $(p=0.241)$ nor in non-inflammatory lesions $(p=0.554)$. No further significant effects were observed.

\section{(a) Inflammatory lesion number}

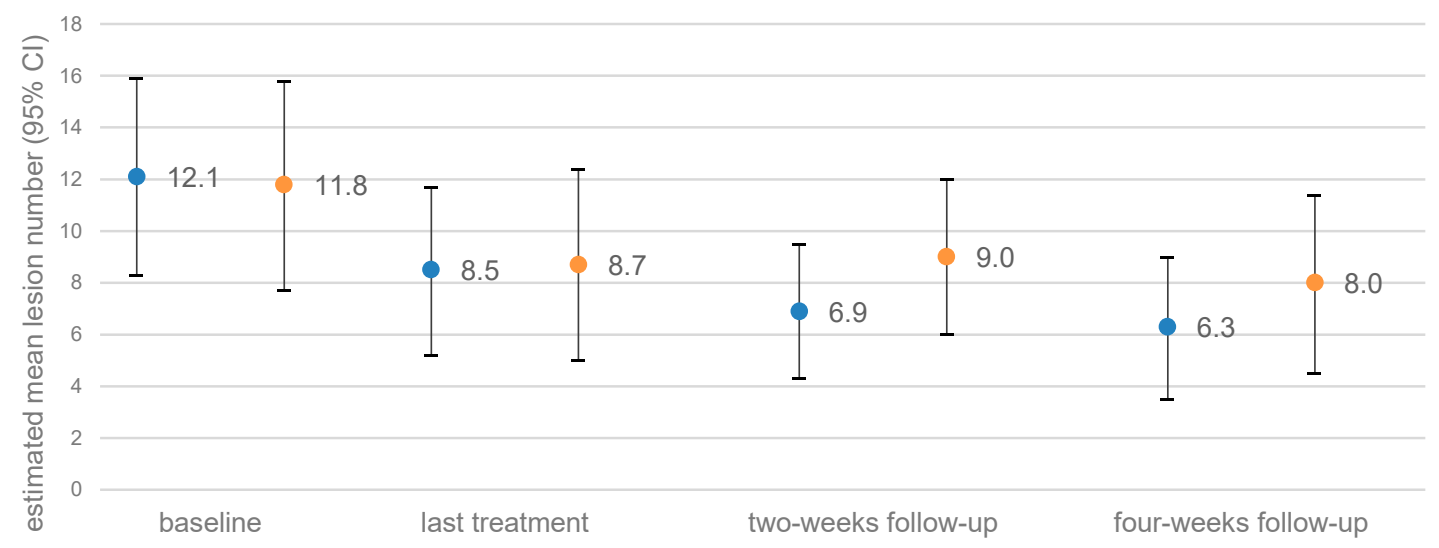

(b) Non-inflammatory lesion number

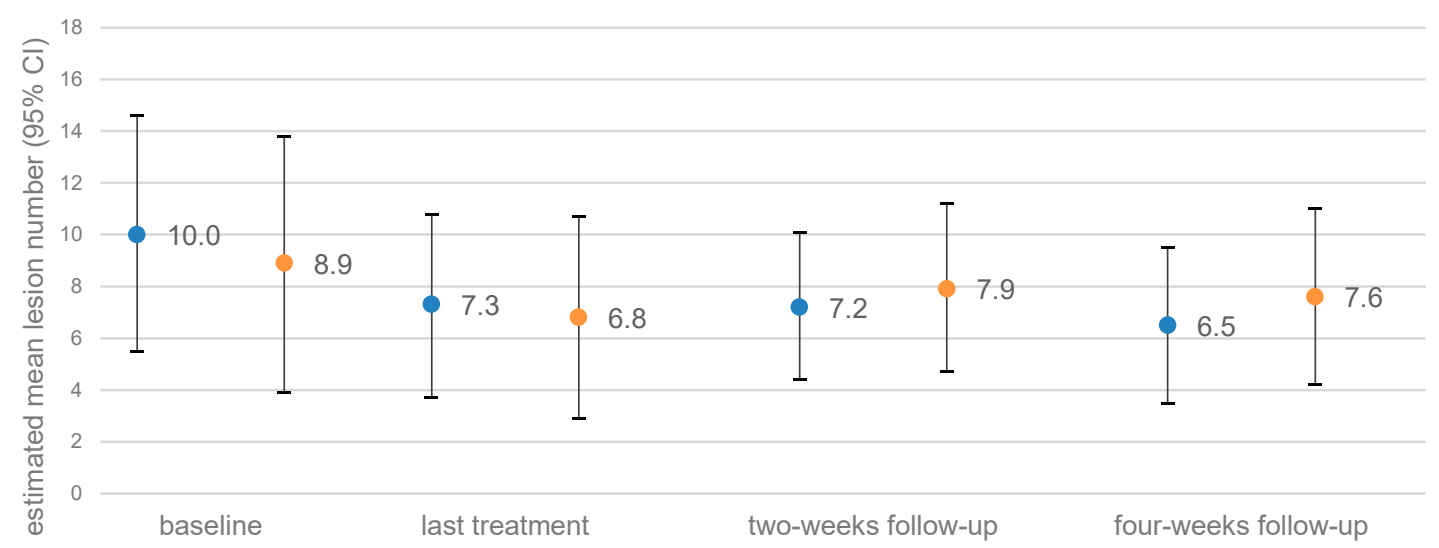

Figure 3. Course of the number of inflammatory lesions (a) and non-inflammatory lesions (b). Blue = treated side; orange $=$ untreated side. Mixed linear models (MLMs) were used to compare the number of lesions between the measurement time points. MLMs additionally included the fixed effects of the number of applied plasma treatments and the interaction of the time and number of applied plasma treatments (data not shown). Presented are the estimated/adjusted means with a corresponding $95 \%$ confidence interval (CI) out of four separate MLMs. In total, 29 patients had a valid lesion count; 25 patients had 10 plasma treatments, and 4 patients 8 treatments. Only inflammatory lesions on the treated side were significantly reduced from baseline to the last treatment $(-30 \%, p=0.020)$, to the two-week follow-up ( $-43 \%$, $p=0.002)$ and the four-week follow-up $(-48 \%, p=0.040)$. 


\subsection{Primary Efficacy Endpoints}

The primary efficacy endpoint related to the difference between the absolute number of lesions at the last treatment and the absolute number of lesions at baseline, and this endpoint was specified for both inflammatory and non-inflammatory lesions.

The difference between the treated and the untreated side with regard to inflammatory lesions was not significant $(p=0.669$, Table 3, Figure 4$)$, neither was the difference in noninflammatory lesions ( $p=0.879$, Table 3 , Figure 4$)$.

An interaction effect of the number and type of treatment was found for inflammatory lesions. The reduction in lesions after 10 treatments was significantly higher on the treated side than on the untreated side (mean difference $=2.1$ lesions, $95 \% \mathrm{CI}=0.4-3.9$ lesions, $p=0.017$, Table 3 ). No further significant differences in the change in inflammatory and non-inflammatory lesions were found ( $p$-values $>0.05$, Table 3$)$.

Table 3. Change in the number of lesions compared between the treated and the untreated side of the face.

\begin{tabular}{|c|c|c|c|c|c|c|c|c|c|c|c|c|}
\hline \multirow{2}{*}{ Change } & \multirow{2}{*}{ Lesions } & \multirow{2}{*}{$\begin{array}{c}\text { Treatment } \\
\text { Number }\end{array}$} & \multicolumn{3}{|c|}{ Treated Side } & \multicolumn{3}{|c|}{ Untreated Side } & \multicolumn{4}{|c|}{$\Delta$} \\
\hline & & & \multirow{2}{*}{$\begin{array}{c}\mathbf{m} \\
-4.3 \\
(-30.3 \%)\end{array}$} & \multicolumn{2}{|c|}{$95 \% \mathrm{CI}$} & \multirow{2}{*}{$\begin{array}{c}\mathbf{m} \\
-3.8 \\
(-27.1 \%)\end{array}$} & \multicolumn{2}{|c|}{$95 \% \mathrm{CI}$} & \multirow{2}{*}{$\begin{array}{c}\mathbf{m} \\
0.5\end{array}$} & \multicolumn{2}{|c|}{$95 \% \mathrm{CI}$} & \multirow{2}{*}{$\begin{array}{c}\boldsymbol{p} \\
0.669\end{array}$} \\
\hline \multirow{6}{*}{$\begin{array}{c}\text { Last } \\
\text { treatment- } \\
\text { baseline }\end{array}$} & \multirow{3}{*}{ inflammatory } & & & -6.2 & -2.3 & & -6.7 & -0.8 & & -1.8 & 2.8 & \\
\hline & & 8 & -4.8 & -8.5 & -1.1 & -5.9 & - & -0.4 & -1.2 & -5.5 & 3.2 & 0.590 \\
\hline & & 10 & -3.8 & -5.2 & -2.3 & -1.6 & $\begin{array}{l}11.5 \\
-3.8\end{array}$ & 0.6 & 2.1 & 0.4 & 3.9 & 0.017 \\
\hline & \multirow{3}{*}{$\begin{array}{c}\text { non- } \\
\text { inflammatory }\end{array}$} & & $\begin{array}{c}-3.2 \\
(-29.1 \%)\end{array}$ & -5.5 & -0.8 & $\begin{array}{c}-3.0 \\
(-27.8 \%)\end{array}$ & -5.6 & -0.5 & 0.14 & -1.7 & 2.0 & 0.879 \\
\hline & & 8 & -3.5 & -7.9 & 0.9 & -4.2 & -8.9 & 0.5 & -0.7 & -4.2 & 2.8 & 0.685 \\
\hline & & 10 & -2.8 & -4.6 & -1.1 & -1.9 & -3.7 & 0.0 & 1.0 & -0.4 & 2.4 & 0.159 \\
\hline \multirow{6}{*}{$\begin{array}{l}\text { Two-week } \\
\text { follow-up to } \\
\text { baseline }\end{array}$} & \multirow{3}{*}{ inflammatory } & & $\begin{array}{c}-6.3 \\
(-44.4 \%)\end{array}$ & -8.4 & -4.1 & $\begin{array}{c}-3.9 \\
(-27.9 \%)\end{array}$ & -6.1 & -1.8 & 2.3 & -0.1 & 4.8 & 0.061 \\
\hline & & 8 & -7.0 & $\begin{array}{c}- \\
11.0\end{array}$ & -3.0 & -4.8 & -8.7 & -0.8 & 2.2 & -2.3 & 6.8 & 0.323 \\
\hline & & 10 & -5.5 & -7.1 & -3.9 & -3.1 & -4.7 & -1.5 & 2.4 & 0.7 & 4.3 & 0.010 \\
\hline & \multirow{3}{*}{$\begin{array}{l}\text { non- } \\
\text { inflammatory }\end{array}$} & & $\begin{array}{c}-3.3 \\
(-30.0 \%)\end{array}$ & -5.8 & -0.8 & $\begin{array}{c}-2.1 \\
(-19.4 \%)\end{array}$ & -4.4 & 0.1 & 2.3 & -1.9 & 4.2 & 0.442 \\
\hline & & 8 & -3.8 & -8.4 & 0.9 & -2.7 & -7.0 & 1.5 & 1.0 & -4.6 & 6.6 & 0.711 \\
\hline & & 10 & -2.8 & -4.7 & -1.0 & -1.5 & -3.2 & 0.1 & 1.3 & -1.0 & 3.5 & 0.254 \\
\hline \multirow{6}{*}{$\begin{array}{l}\text { Four-week } \\
\text { follow-up to } \\
\text { baseline }\end{array}$} & \multirow{3}{*}{ inflammatory } & & $\begin{array}{c}-7.4 \\
(-52.1 \%)\end{array}$ & $\begin{array}{c}- \\
10.1\end{array}$ & -4.8 & $\begin{array}{c}-5.7 \\
(-40.7 \%)\end{array}$ & -9.0 & -2.3 & 1.8 & -0.1 & 3.7 & 0.068 \\
\hline & & 8 & -8.7 & $\begin{array}{c}- \\
13.6\end{array}$ & -3.7 & -7.3 & $\begin{array}{c}- \\
13.5\end{array}$ & -1.1 & 1.3 & -2.2 & 4.9 & 0.449 \\
\hline & & 10 & -6.2 & -8.2 & -4.3 & -4.0 & -6.5 & -1.6 & 2.2 & -3.7 & -0.8 & 0.003 \\
\hline & \multirow{3}{*}{$\begin{array}{c}\text { non- } \\
\text { inflammatory }\end{array}$} & & $\begin{array}{c}-4.0 \\
(-36.4 \%)\end{array}$ & -6.8 & -1.2 & $\begin{array}{c}-2.5 \\
(-23.1 \%)\end{array}$ & -4.9 & -0.1 & 1.5 & -1.2 & 4.3 & 0.263 \\
\hline & & 8 & -4.5 & -9.8 & 0.7 & -3.5 & -8.0 & 1.0 & 1.0 & -4.1 & 6.1 & 0.693 \\
\hline & & 10 & -3.5 & -5.6 & -1.4 & -1.4 & -3.2 & 0.4 & 2.1 & 0.0 & 4.1 & 0.047 \\
\hline
\end{tabular}

Mixed linear models (MLMs) were used to compare the change in the number of lesions between the treated and the untreated side. MLMs additionally included the number of applied plasma treatments and the number of lesions at baseline. Presented are the estimated/adjusted means including 95\% confidence interval (CI) out of six separate MLMs (two types of lesions $\times$ three time points). For both types of lesions, the mean change in the number of lesions is additionally presented as mean change in percentage. Moreover, mean differences $(\Delta)$ of mean change in the number of lesions including 95\% CI are presented. In total, 29 patients had a valid lesion count; 25 patients had 10 plasma treatments, and 4 patients had 8 treatments. 


\section{(a) Inflammatory lesion change}

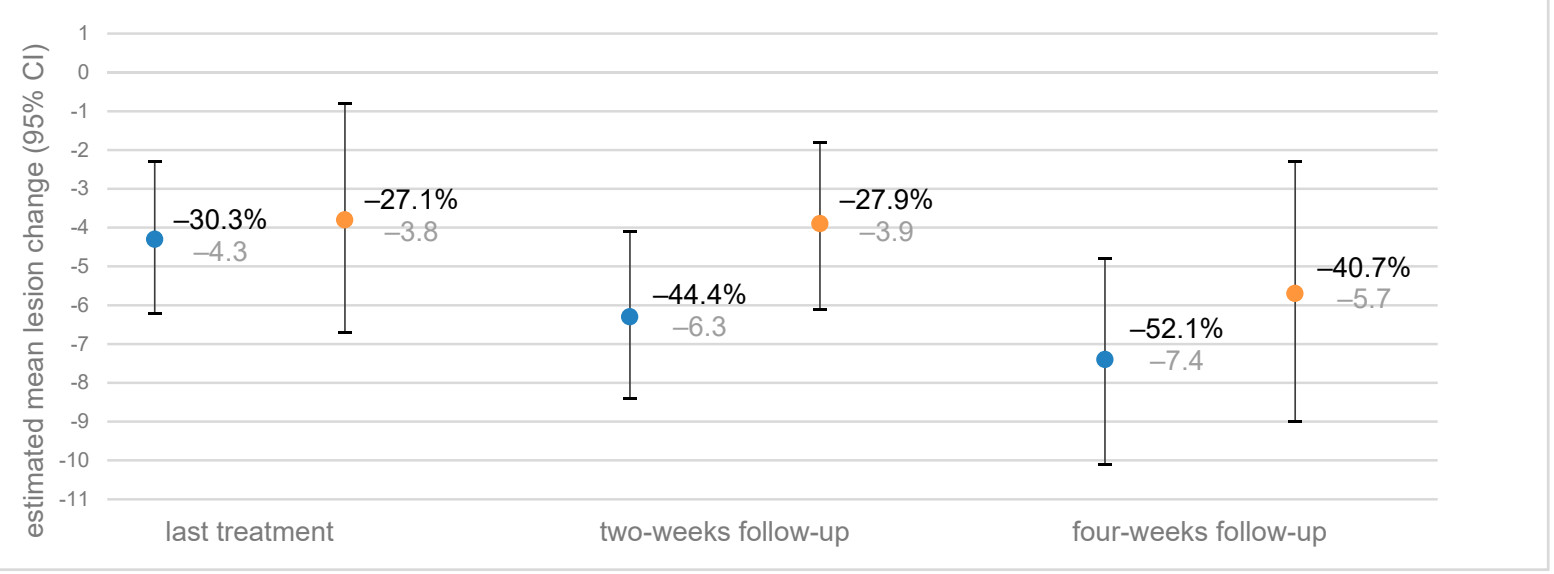

(b) Non-inflammatory lesion change

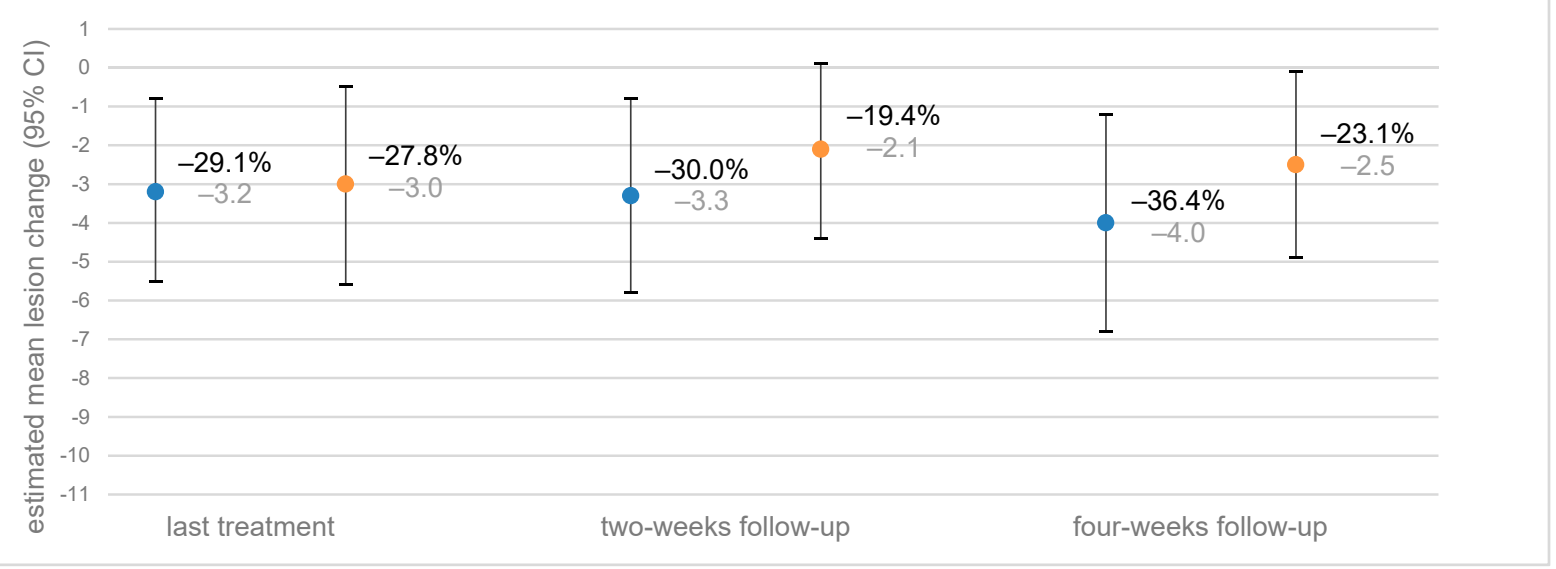

Figure 4. Primary and secondary efficacy endpoints: change in inflammatory lesions (a) and non-inflammatory lesions (b). Blue $=$ treated side; orange $=$ non-treated side. Mixed linear models (MLMs) were used to compare the change in the number of inflammatory and non-inflammatory lesions between the treated and the non-treated side. MLMs additionally included the fixed effects of the number of applied plasma treatments, the type of treatment, the interaction of the treatment type with the number of applied plasma treatments and the baseline number of lesions. Presented are the estimated/adjusted means with corresponding 95\% confidence interval (CI) out of six separate MLMs (three time points and two types of lesion). The mean change in the number of lesions was additionally presented as mean change in percentage. In total, 29 patients had a valid lesion count; 25 patients had 10 plasma treatments, and 4 patients 8 treatments. Mean reduction in the number of lesions did not significantly differ between the treated side and the untreated side.

\subsection{Secondary Efficacy Endpoints}

3.6.1. Change in Lesions until the Two- and Four-Week Follow-Ups

At each follow-up, the number of inflammatory and non-inflammatory lesions was reduced on both sides of the face (Figure 4). In general, the reduction in lesions tended to be higher on the treated than on the untreated side, but there was no significant difference in mean reduction between the two treatment sides ( $p$-values $>0.05$, Table 3 ). Inflammatory lesions tended to respond better to plasma treatment than non-inflammatory lesions (Figure 4). Except for non-inflammatory lesions on the untreated side, the mean reduction in lesions from baseline tended to increase with time (Figure 4).

The reduction in lesions after 10 treatments was significantly higher for inflammatory lesions on the treated side than on the untreated side at the two- and four-week follow- 
ups as well as for non-inflammatory lesions at the four-week follow-up ( $p$-values $<0.05$, Table 3).

\subsubsection{Subjective Aesthetic Change}

Subjective aesthetic change (GAIS) was measured at the last treatment as well as two and four weeks after treatment completion. The percentage of patients reporting improved aesthetics was higher for the treated side than for the untreated side at treatment completion (79\% vs. $45 \%$ ) and at the two-week follow-up (72\% vs. $45 \%$ ) and the four-week follow-up (79\% vs. 52\%) ( $p$-values $<0.05$, Table 4 ).

Table 4. Comparison of the Global Aesthetic Improvement Scale between the treated and the untreated side of the face.

\begin{tabular}{|c|c|c|c|c|c|c|}
\hline \multicolumn{7}{|c|}{ Untreated Side } \\
\hline \multicolumn{2}{|c|}{ Treated Side } & Worse & No Change & Improved & Total & $p$ \\
\hline \multirow{4}{*}{ last treatment } & worse & 1 & 0 & 0 & 1 & \multirow{4}{*}{0.004} \\
\hline & no change & 0 & 4 & 1 & 5 & \\
\hline & improved & 0 & 11 & 12 & 23 & \\
\hline & total & 1 & 15 & 13 & 29 & \\
\hline \multirow{4}{*}{$\begin{array}{l}\text { two-week } \\
\text { follow-up }\end{array}$} & worse & 1 & 0 & 0 & 1 & \multirow{4}{*}{0.008} \\
\hline & no change & 1 & 5 & 1 & 7 & \\
\hline & improved & 1 & 8 & 12 & 21 & \\
\hline & total & 3 & 13 & 13 & 29 & \\
\hline \multirow{4}{*}{$\begin{array}{l}\text { four-week } \\
\text { follow-up }\end{array}$} & worse & 1 & 0 & 0 & 1 & \multirow{4}{*}{0.013} \\
\hline & no change & 0 & 4 & 1 & 5 & \\
\hline & improved & 1 & 8 & 14 & 23 & \\
\hline & total & 2 & 12 & 11 & 29 & \\
\hline
\end{tabular}

Blue diagonal = same aesthetic change rating for the treated and the untreated side; below blue diagonal = aesthetic change rating better for the treated side; above blue diagonal = aesthetic change rating better for the untreated side.

\subsubsection{Acne Severity}

Acne severity (IGA) was assessed by a blinded physician for each side of the face at baseline, at the last treatment as well as two and four weeks after the last treatment. At baseline, all patients had moderate acne severity on both sides of the face. Acne severity ratings by the physician did not significantly differ between the treated and the untreated side ( $p$-values $>0.05$ ). Table 5 presents the IGA scores for the treated and the untreated side of the face.

Table 5. Comparison of the Investigator Global Assessment between the treated and the untreated side of the face.

\begin{tabular}{|c|c|c|c|c|c|c|}
\hline \multicolumn{7}{|c|}{ Untreated Side } \\
\hline \multicolumn{2}{|c|}{ Treated Side } & $\begin{array}{c}\text { Almost Clear } \\
\text { Skin }\end{array}$ & Mild & Moderate & Total & $p$ \\
\hline \multirow{4}{*}{$\begin{array}{c}\text { last } \\
\text { treatment }\end{array}$} & almost clear skin & 0 & 1 & 0 & \multirow{4}{*}{$\begin{array}{c}1 \\
16 \\
11 \\
28\end{array}$} & \multirow{4}{*}{0.132} \\
\hline & mild & 0 & 9 & 7 & & \\
\hline & moderate & 0 & 3 & 8 & & \\
\hline & total & 0 & 13 & 15 & & \\
\hline \multirow{4}{*}{$\begin{array}{l}\text { two-week } \\
\text { follow-up }\end{array}$} & almost clear skin & 1 & 2 & 0 & 3 & \multirow{4}{*}{0.132} \\
\hline & mild & 0 & 7 & 6 & 13 & \\
\hline & moderate & 0 & 3 & 10 & 13 & \\
\hline & total & 1 & 12 & 16 & 29 & \\
\hline \multirow{4}{*}{$\begin{array}{l}\text { four-week } \\
\text { follow-up }\end{array}$} & almost clear skin & 0 & 0 & 0 & 0 & \multirow{4}{*}{0.157} \\
\hline & mild & 1 & 13 & 6 & 20 & \\
\hline & moderate & 0 & 1 & 8 & 9 & \\
\hline & total & 1 & 14 & 14 & 29 & \\
\hline
\end{tabular}

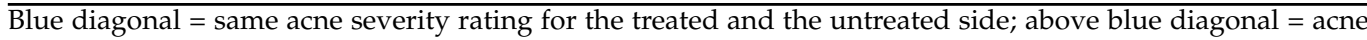
severity rating better for the treated side; below blue diagonal = acne severity rating better for the untreated side. 


\section{Discussion}

In this first controlled clinical trial with a split face design, CAP (8-10 treatments within four to six weeks) was shown to be a safe and effective method for treating moderate facial acne in adults. The treated side of the face showed a significant and continuous decrease in inflammatory acne lesions from baseline to the last treatment $(-30 \%)$ as well as to the two-week follow-up $(-44 \%)$ and the four-week follow-up ( $-52 \%)$. No significant reduction was found for non-inflammatory lesions on the treated side and for inflammatory and non-inflammatory lesions on the untreated side. The mean absolute change in acne lesions did not significantly differ between the treated and the untreated side from baseline to the last treatment and the two- and four-week follow-ups, although the treated side showed a clear trend for an increased reduction in lesions. Indeed, significant differences between the treated and the untreated side were found in the subgroup of patients who had received 10 instead of $8 \mathrm{CAP}$ treatments. After 10 treatments, the reduction in inflammatory acne lesions was significantly higher on the treated side than on the untreated side at the time of treatment completion as well as at the two- and four-week follow-ups. In general, inflammatory acne lesions responded better to CAP treatment than non-inflammatory lesions. Significant differences were also found for the subjective aesthetic change as measured by means of the GAIS. The percentage of patients reporting improved aesthetics was higher for the treated side than for the untreated side at the last treatment (79\% vs. $45 \%)$ and at two-week ( $72 \%$ vs. $45 \%$ ) and four-week follow-ups (79\% vs. $52 \%$ ). The physicians ratings of aesthetics (GAIS) and the physicians' acne severity ratings (IGA) however, did not yield significant differences between the treated and the untreated side after therapy.

The major pathogenetic factors in the development of acne are increased sebum production by hyperplastic sebaceous glands, follicular hyperkeratinisation, bacterial hypercolonisation of the follicle and immune reactions triggering inflammation [28]. Cutibacterium acnes contributes to the formation of micro-comedones and inflammatory lesions, triggering the secretion of proinflammatory cytokines, such as interleukin (IL)- $1 \alpha$, IL8 and tumour necrosis factor (TNF)- $\alpha$ through activation of toll-like receptors (TLR) [29-31]. The rationale for using CAP to treat acne was the assumption that CAP may target some of these causative factors. CAP has been shown to inactivate Cutibacterium acnes grown on culture media in planktonic and even in biofilm state in a time-dependent manner [32]. In addition, CAP uses hair as a conductor that transports the plasma deep into the hair follicles, thus enabling local antisepsis of the follicular reservoir [27]. In an in vivo animal model, CAP induced energy-dependent microscopic changes in the follicular epithelium and the sebaceous glands [33]. The authors suggest that sebaceous glands can be selectively modified or damaged by selecting the proper gaseous sources for generating CAP with regulated energy settings. Furthermore, CAP modulates the induction of several cytokines and growth factors in wound healing (e.g., IL-1, IL-6, IL-8, TNF- $\alpha$, B-defensins and matrix metalloproteinases), which also play a pathogenetic role in acne [34-37]. Thus, it can be hypothesised that CAP effects on acne result from inactivation of Cutibacterium acnes, alteration of the follicular milieu and reduced sebum production as well as from immunomodulatory and anti-inflammatory effects.

Cold plasma has been studied with regard to its use for the treatment of several dermatological conditions, but controlled clinical studies on acne are still lacking. In an uncontrolled study conducted in Thailand, a Direct Barrier Discharge air plasma contact skin-type electrode (called BioPlasma device) was used for acne treatment. 30 volunteers had one side of their face treated with BioPlasma once per week for four weeks [38]. A sebum reduction in up to $80 \%$ of cases was measured by a sebumeter. The effect of oil reduction lasted until four weeks after treatment cessation, which could explain why, in our study, the number of acne lesions further decreased up to four weeks after treatment cessation. However, the study from Thailand did not report any further details about patients, methodology and results. Arisi et al. treated 2 patients with mild to moderate facial acne with CAP, using a plasma torch producing argon plasma (SteriPlas, Adtec Healthcare), which resulted in a reduction in acne lesions after treatment [39]. Sebum 
excretion parameters, as measured by sebometry and trans-epidermal water loss, also improved as compared to base values. These preliminary studies together with the results of our study confirm the potential of different CAP devices for this new indication.

The cold plasma device used in this study was the BioWeld1 System, which is CEmarked for surgical wound closure. Treatment with the BioWeld1 system included CAPexposure of each skin segment for no more than 20 s per day including a minimal UVexposure well below the maximum exposure according to the American Conference of Governmental Industrial Hygienists (ACGIH) guidelines. Thus, no UV-induced side effects such as eye damage or sun burn had to be expected. The application of CAP was quick and comfortable for the patients. Patients tolerated the treatment very well, and only two mild AEs relating to pain and no SAE were documented. In comparison with other topical and systemic treatment modalities for acne, there is no other conventional therapy with such a favourable spectrum of side effects. For moderate acne, guidelines recommend therapies combining benzoyl peroxide (BPO), retinoids and topical or systemic antibiotics [1,40]. Although oral antibiotics remain one of the main options for treating moderate to severe acne, current guidelines strongly advocate limiting their use due to rising concerns of antibiotic resistance $[40,41]$. In this context, CAP could become a new therapeutic alternative with a completely different and mainly physical mode of action that warrants to be further explored in larger studies that also include patients of younger age.

In our study, CAP treatment led to a continuous reduction in acne lesions with the maximal decrease of about $-50 \%$ in inflammatory acne lesions and $-36 \%$ in non-inflammatory acne lesions (as compared to $-41 \%$ and $-23 \%$ on the untreated side, differences not significant) at the four-week follow-up. Interestingly, the lesion counts continued to show a decrease in lesions after the last CAP treatment until the four-week follow-up, indicating that CAP continues to be efficacious beyond treatment cessation. Efficacy of CAP was superior for inflammatory lesions than for non-inflammatory lesion, as is also known for most other acne therapies. A meta-analysis of placebo-controlled trials indicated that oral minocycline was more active than placebo against inflammatory acne lesions, producing a $-45.5 \%$ reduction compared to $-32.0 \%$ for placebo after twelve weeks of therapy [42]. The effect against non-inflammatory acne lesions was smaller with $-14.9 \%$ versus $-6.3 \%$ after placebo. For topical acne treatments, the reduction in inflammatory lesions after twelve weeks of therapy ranges from $-44 \%$ to $-72 \%$ for $\mathrm{BPO}$, from -46 to $-57 \%$ for adapalene, and from $-62 \%$ to $-70 \%$ for a combination of BPO and adapalene [43]. With a mean reduction in inflammatory acne lesions of about $-50 \%$ after a study period of ten to twelve weeks, CAP seems to be slightly less effective than conventional topical treatments but shows much better skin tolerability.

An obvious limitation of this study is the non-achievement of the recruitment goal due to the sponsor's decision to close the study prematurely. Nevertheless, the effects were robust enough so that they were detectable in a smaller sample size. Another limitation is that we were not allowed to include patients younger than 18 years by the authorities (BfArM), although acne shows the highest incidence in teenagers. Thus, we cannot be sure that the results obtained in this study would have been the same in younger patients. Several questions remain unanswered in this first controlled trial and should be addressed in further studies. The optimal duration and frequency of CAP treatment have yet to be determined. A longer treatment duration would probably improve efficacy because $10 \mathrm{CAP}$ treatments already showed better results than $8 \mathrm{CAP}$ treatments. A longer followup would help to define how long the therapeutic effect lasts and if maintenance therapy is necessary to prevent relapses and sustain the achieved improvement. Since studies have shown that CAP treatment of lesions after laser ablation leads to healing with aesthetically pleasing results [44]; CAP treatment could possibly also reduce scarring in patients with acne. The mechanisms of action by which CAP exerts its anti-inflammatory effects in acne still have to be examined in more detail. Studies are desirable that also measure the extent of colonisation with microbiota in pilosebaceous units, including the antibiotic resistance status before and after CAP treatment. Also, the microbial composition of the skin should 
be studied before and after CAP treatment to clarify if CAP also influences the steady-state cutaneous microbiome. Finally, patient adherence to CAP treatment could be fostered by future developments of low-cost and easy-to-handle plasma devices that can be purchased by or lent to patients for home use.

\section{Conclusions}

In conclusion, CAP turned out to be a safe treatment option, showed moderate reduction in acne lesions and led to higher patient-based ratings of aesthetics than nontreatment. Because of the premature closure of the trial, results should be replicated in a larger Phase III trial.

Author Contributions: Conceptualization, S.K., M.K. and M.B.; methodology, S.K., M.K.; software, K.M.; validation, K.M. and F.Z.; formal analysis, K.M., F.Z. and M.K.; investigation, S.K., M.B.; resources, S.K.; data curation, K.M. and F.Z. writing - original draft preparation, S.K.; writingreview and editing, S.K., M.B., M.K. and K.M.; visualization, K.M.; supervision, M.B.; project administration, S.K. and M.K.; funding acquisition, S.K. All authors have read and agreed to the published version of the manuscript.

Funding: This research was funded by IONMED Ltd., Yokneam, Israel.

Institutional Review Board Statement: This study was conducted in accordance with the German Medical Device Law (\$22a Medizinproduktegesetz, MPG), the Harmonised Tripartite Guideline for Good Clinical Practice (ICH-GCP E6), the International Standard Organization (ISO); ISO 141551; ISO 14155-2, and the Declaration of Helsinki (64th WMA General Assembly, Fortaleza, Brazil, October 2013). The study was approved by the Ethics Committee of the University of Regensburg (reference number: 16-121-0120) and the German Federal Institute for Drugs and Medical Devices (BfArM, reference number: 94.1.01-5660-10252). The study was registered with the study register DRKS (Deutsches Register Klinischer Studien, registration number DRKS00025008), was submitted to the WHO and is searchable via its Meta-registry (http:/ / apps.who.int/trialsearch, (accessed on 7 April 2021)).

Informed Consent Statement: Informed consent was obtained from all subjects involved in the study.

Data Availability Statement: Data supporting reported results can be found in the archives of the University Hospital Regensburg.

Conflicts of Interest: The authors declare no conflict of interest.

\section{References}

1. Nast, A.; Dreno, B.; Bettoli, V.; Bukvic Mokos, Z.; Degitz, K.; Dressler, C.; Finlay, A.Y.; Haedersdal, M.; Lambert, J.; Layton, A.; et al. European evidence-based (S3) guideline for the treatment of acne-Update 2016-Short version. J. Eur. Acad. Dermatol. Venereol. 2016, 30, 1261-1268. [CrossRef]

2. Leung, A.K.C.; Barankin, B. Dermatology: How to manage acne vulgaris. Drugs Context. 2021, 10. [CrossRef]

3. Heng, A.H.S.; Chew, F.T. Systematic review of the epidemiology of acne vulgaris. Sci. Rep. 2020, 10, 5754. [CrossRef] [PubMed]

4. Walsh, T.R.; Efthimiou, J.; Dreno, B. Systematic review of antibiotic resistance in acne: An increasing topical and oral threat. Lancet Infect. Dis. 2016, 16, 23-33. [CrossRef]

5. Brany, D.; Dvorska, D.; Halasova, E.; Skovierova, H. Cold Atmospheric Plasma: A Powerful Tool for Modern Medicine. Int. J. Mol. Sci. 2020, 21, 2932. [CrossRef]

6. Heinlin, J.; Isbary, G.; Stolz, W.; Morfill, G.; Landthaler, M.; Shimizu, T.; Steffes, B.; Nosenko, T.; Zimmermann, J.; Karrer, S. Plasma applications in medicine with a special focus on dermatology. J. Eur. Acad. Dermatol. Venereol. 2011, 25, 1-11. [CrossRef] [PubMed]

7. Izadjoo, M.; Zack, S.; Kim, H.; Skiba, J. Medical applications of cold atmospheric plasma: State of the science. J. Wound Care 2018, 27, S4-S10. [CrossRef]

8. Kong, M.G.; Kroesen, G.; Morfill, G.; Nosenko, T.; Shimizu, T.; van Dijk, J.; Zimmermann, J.L. Plasma medicine: An introductory review. New J. Phys. 2009, 11, 115012. [CrossRef]

9. Heinlin, J.; Maisch, T.; Zimmermann, J.L.; Shimizu, T.; Holzmann, T.; Simon, M.; Heider, J.; Landthaler, M.; Morfill, G.; Karrer, S. Contact-free inactivation of Trichophyton rubrum and Microsporum canis by cold atmospheric plasma treatment. Future Microbiol. 2013, 8, 1097-1106. [CrossRef]

10. Maisch, T.; Shimizu, T.; Isbary, G.; Heinlin, J.; Karrer, S.; Klampfl, T.G.; Li, Y.F.; Morfill, G.; Zimmermann, J.L. Contact-free inactivation of Candida albicans biofilms by cold atmospheric air plasma. Appl. Environ. Microbiol. 2012, 78, 4242-4247. [CrossRef] 
11. Maisch, T.; Shimizu, T.; Li, Y.F.; Heinlin, J.; Karrer, S.; Morfill, G.; Zimmermann, J.L. Decolonisation of MRSA, S-aureus and E-coli by Cold-Atmospheric Plasma Using a Porcine Skin Model In Vitro. PLoS ONE 2012, 7, e34610. [CrossRef] [PubMed]

12. Scholtz, V.; Pazlarova, J.; Souskova, H.; Khun, J.; Julak, J. Nonthermal plasma-A tool for decontamination and disinfection. Biotechnol. Adv. 2015, 33, 1108-1119. [CrossRef]

13. Wiegand, C.; Beier, O.; Horn, K.; Pfuch, A.; Tolke, T.; Hipler, U.C.; Schimanski, A. Antimicrobial impact of cold atmospheric pressure plasma on medical critical yeasts and bacteria cultures. Skin Pharmacol. Physiol. 2014, 27, 25-35. [CrossRef] [PubMed]

14. Isbary, G.; Heinlin, J.; Shimizu, T.; Zimmermann, J.L.; Morfill, G.; Schmidt, H.U.; Monetti, R.; Steffes, B.; Bunk, W.; Li, Y.; et al. Successful and safe use of 2 min cold atmospheric argon plasma in chronic wounds: Results of a randomized controlled trial. Br. J. Dermatol. 2012, 167, 404-410. [CrossRef] [PubMed]

15. Isbary, G.; Morfill, G.; Schmidt, H.U.; Georgi, M.; Ramrath, K.; Heinlin, J.; Karrer, S.; Landthaler, M.; Shimizu, T.; Steffes, B.; et al. A first prospective randomized controlled trial to decrease bacterial load using cold atmospheric argon plasma on chronic wounds in patients. Br. J. Dermatol. 2010, 163, 78-82. [CrossRef]

16. Isbary, G.; Stolz, W.; Shimizu, T.; Monetti, R.; Bunk, W.; Schmidt, H.-U.; Morfill, G.E.; Klämpfl, T.; Steffes, B.; Thomas, H. Cold atmospheric argon plasma treatment may accelerate wound healing in chronic wounds: Results of an open retrospective randomized controlled study in vivo. Clin. Plasma Med. 2013, 1, 25-30. [CrossRef]

17. Moelleken, M.; Jockenhofer, F.; Wiegand, C.; Buer, J.; Benson, S.; Dissemond, J. Pilot study on the influence of cold atmospheric plasma on bacterial contamination and healing tendency of chronic wounds. J. Dtsch. Dermatol. Ges. 2020, 18, 1094-1101. [CrossRef] [PubMed]

18. Stratmann, B.; Costea, T.C.; Nolte, C.; Hiller, J.; Schmidt, J.; Reindel, J.; Masur, K.; Motz, W.; Timm, J.; Kerner, W.; et al. Effect of Cold Atmospheric Plasma Therapy vs. Standard Therapy Placebo on Wound Healing in Patients With Diabetic Foot Ulcers: A Randomized Clinical Trial. JAMA Netw Open 2020, 3, e2010411. [CrossRef]

19. Ulrich, C.; Kluschke, F.; Patzelt, A.; Vandersee, S.; Czaika, V.A.; Richter, H.; Bob, A.; von Hutten, J.; Painsi, C.; Hugel, R.; et al. Clinical use of cold atmospheric pressure argon plasma in chronic leg ulcers: A pilot study. J. Wound Care 2015, 24, 196-203. [CrossRef]

20. Heinlin, J.; Zimmermann, J.L.; Zeman, F.; Bunk, W.; Isbary, G.; Landthaler, M.; Maisch, T.; Monetti, R.; Morfill, G.; Shimizu, T.; et al. Randomized placebo-controlled human pilot study of cold atmospheric argon plasma on skin graft donor sites. Wound Repair Regen. 2013, 21, 800-807. [CrossRef] [PubMed]

21. Isbary, G.; Shimizu, T.; Zimmermann, J.; Heinlin, J.; Al-Zaabi, S.; Rechfeld, M.; Morfill, G.; Karrer, S.; Stolz, W. Randomized placebo-controlled clinical trial showed cold atmospheric argon plasma relieved acute pain and accelerated healing in herpes zoster. Clin. Plasma Med. 2014, 2, 50-55. [CrossRef]

22. Bogle, M.A.; Arndt, K.A.; Dover, J.S. Evaluation of plasma skin regeneration technology in low-energy full-facial rejuvenation. Arch. Dermatol. 2007, 143, 168-174. [CrossRef]

23. Wirtz, M.; Stoffels, I.; Dissemond, J.; Schadendorf, D.; Roesch, A. Actinic keratoses treated with cold atmospheric plasma. J. Eur. Acad. Dermatol. Venereol. 2018, 32, 37-39. [CrossRef]

24. Boxhammer, V.; Li, Y.F.; Koritzer, J.; Shimizu, T.; Maisch, T.; Thomas, H.M.; Schlegel, J.; Morfill, G.E.; Zimmermann, J.L. Investigation of the mutagenic potential of cold atmospheric plasma at bactericidal dosages. Mutat. Res.-Genet. Toxicol. Environ. 2013, 753, 23-28. [CrossRef] [PubMed]

25. Maisch, T.; Bosserhoff, A.; Unger, P.; Heider, J.; Shimizu, T.; Zimmermann, J.; Morfill, G.; Landthaler, M.; Karrer, S. Investigation of toxicity and mutagenicity of cold atmospheric argon plasma. Environ. Mol. Mutagen. 2017, 58, 172-177. [CrossRef] [PubMed]

26. Wende, K.; Bekeschus, S.; Schmidt, A.; Jatsch, L.; Hasse, S.; Weltmann, K.; Masur, K.; von Woedtke, T. Risk assessment of a cold argon plasma jet in respect to its mutagenicity. Mutat. Res.-Genet. Toxicol. Environ. 2016, 798, 48-54. [CrossRef]

27. Lademann, O.; Kramer, A.; Richter, H.; Patzelt, A.; Meinke, M.C.; Roewert-Huber, J.; Czaika, V.; Weltmann, K.D.; Hartmann, B.; Koch, S. Antisepsis of the follicular reservoir by treatment with tissue-tolerable plasma (TTP). Laser Phys. Lett. 2011, 8, 313-317. [CrossRef]

28. Williams, H.C.; Dellavalle, R.P.; Garner, S. Acne vulgaris. Lancet 2012, 379, 361-372. [CrossRef]

29. Graham, G.M.; Farrar, M.D.; Cruse-Sawyer, J.E.; Holland, K.T.; Ingham, E. Proinflammatory cytokine production by human keratinocytes stimulated with Propionibacterium acnes and P. acnes GroEL. Br. J. Dermatol. 2004, 150, 421-428. [CrossRef]

30. Leyden, J. Current issues in antimicrobial therapy for the treatment of acne. J. Eur. Acad. Dermatol. Venereol. 2001, 15, 51-55. [CrossRef]

31. Patel, D.J.; Bhatia, N. Oral Antibiotics for Acne. Am. J. Clin. Dermatol. 2021, 22, 193-204. [CrossRef] [PubMed]

32. Ali, A.; Kim, Y.H.; Lee, J.Y.; Lee, S.; Uhm, H.S.; Cho, G.; Park, B.J.; Choi, E.H. Inactivation of Propionibacterium acnes and its biofilm by non-thermal plasma. Curr. Appl. Phys. 2014, 14, S142-S148. [CrossRef]

33. Kim, H.; Kim, H.J.; Kim, H.K.; Hong, J.Y.; Cho, S.B. Effects of argon and nitrogen plasma pulses on the skin and skin appendages in an in vivo animal model. Skin Res. Technol. 2020, 26, 81-90. [CrossRef]

34. Arndt, S.; Landthaler, M.; Zimmermann, J.L.; Unger, P.; Wacker, E.; Shimizu, T.; Li, Y.-F.; Morfill, G.E.; Bosserhoff, A.-K.; Karrer, S. Effects of cold atmospheric plasma (CAP) on B-defensins, inflammatory cytokines, and apoptosis-related molecules in keratinocytes in vitro and in vivo. PLoS ONE 2015, 10, 0120041. [CrossRef] [PubMed]

35. Arndt, S.; Schmidt, A.; Karrer, S.; von Woedtke, T. Comparing two different plasma devices kINPen and Adtec SteriPlas regarding their molecular and cellular effects on wound healing. Clin. Plasma Med. 2018, 9, 24-33. [CrossRef] 
36. Arndt, S.; Unger, P.; Wacker, E.; Shimizu, T.; Heinlin, J.; Li, Y.-F.; Thomas, H.M.; Morfill, G.E.; Zimmermann, J.L.; Bosserhoff, A.-K. Cold atmospheric plasma (CAP) changes gene expression of key molecules of the wound healing machinery and improves wound healing in vitro and in vivo. PLoS ONE 2013, 8, 79325. [CrossRef]

37. Barton, A.; Hasse, S.; Bundscherer, L.; Wende, K.; Weltmann, K.; Lindequist, U.; Masur, K. Growth factors and cytokines are regulated by non-thermal atmospheric pressure plasma: P034. Exp. Dermatol. 2014, 23, e2-e52.

38. Chutsirimongkol, C.; Boonyawan, D.; Polnikorn, N.; Techawatthanawisan, W.; Kundilokchai, T. Non-thermal plasma for acne and aesthetic skin improvement. Plasma Med. 2014, 4, 79-88. [CrossRef]

39. Mariachiara, A.; Anna, V.; Alessandra, G.; Edoardo, G.P.; Stefania, B.; Mariateresa, R.; Piergiacomo, C.-P. Cold atmospheric plasma (CAP) as a promising therapeutic option for mild to moderate acne vulgaris: Clinical and non-invasive evaluation of two cases. Clin. Plasma Med. 2020, 19, 100110. [CrossRef]

40. Conforti, C.; Chello, C.; Giuffrida, R.; di Meo, N.; Zalaudek, I.; Dianzani, C. An overview of treatment options for mild-tomoderate acne based on American Academy of Dermatology, European Academy of Dermatology and Venereology, and Italian Society of Dermatology and Venereology guidelines. Dermatol. Ther. 2020, 33, 13548. [CrossRef]

41. Baldwin, H. Oral Antibiotic Treatment Options for Acne Vulgaris. J. Clin. Aesthet. Dermatol. 2020, 13, 26-32. [PubMed]

42. Garner, S.E.; Eady, A.; Bennett, C.; Newton, J.N.; Thomas, K.; Popescu, C.M. Minocycline for acne vulgaris: Efficacy and safety. Cochrane Database Syst. Rev. 2013. [CrossRef]

43. Kim, S.Y.; Ochsendorf, F.R. New developments in acne treatment: Role of combination adapalene-benzoylperoxide. Ther. Clin. Risk Manag. 2016, 12, 1497. [CrossRef] [PubMed]

44. Metelmann, H.-R.; Vu, T.T.; Do, H.T.; Le, T.N.B.; Hoang, T.H.A.; Phi, T.T.T.; Luong, T.M.L.; Nguyen, T.T.H.; Nguyen, T.H.M.; Nguyen, T.L. Scar formation of laser skin lesions after cold atmospheric pressure plasma (CAP) treatment: A clinical long term observation. Clin. Plasma Med. 2013, 1, 30-35. [CrossRef] 